\title{
Review Article \\ Ex Situ Conservation of Biodiversity with Particular Emphasis to Ethiopia
}

\author{
Mohammed Kasso and Mundanthra Balakrishnan \\ Department of Zoological Sciences, Addis Ababa University, P.O. Box 1176, Addis Ababa, Ethiopia \\ Correspondence should be addressed to Mohammed Kasso; muhesofi@yahoo.com
}

Received 26 August 2013; Accepted 16 September 2013

Academic Editors: I. Bisht and D. Schmeller

Copyright (C) 2013 M. Kasso and M. Balakrishnan. This is an open access article distributed under the Creative Commons Attribution License, which permits unrestricted use, distribution, and reproduction in any medium, provided the original work is properly cited.

\begin{abstract}
Biodiversity encompasses variety and variability of all forms of life on earth that play a great role in human existence. Its conservation embraces maintenance, sustainable utilization, and restoration, of the lost and degraded biodiversity through two basic and complementary strategies called in situ and ex situ. Ex situ conservation is the technique of conservation of all levels of biological diversity outside their natural habitats through different techniques like zoo, captive breeding, aquarium, botanical garden, and gene bank. It plays key roles in communicating the issues, raising awareness, and gaining widespread public and political support for conservation actions and for breeding endangered species in captivity for reintroduction. Limitations of ex situ conservation include maintenance of organisms in artificial habitats, deterioration of genetic diversity, inbreeding depression, adaptations to captivity, and accumulation of deleterious alleles. It has many constraints in terms of personnel, costs, and reliance on electric power sources. Ethiopia is considered to be one of the richest centers of genetic resources in the world. Currently, a number of stakeholders/actors are actively working on biodiversity conservation through ex situ conservation strategies by establishing gene banks, botanical garden, and zoo.
\end{abstract}

\section{Introduction}

According to the Convention on Biological Diversity, biodiversity refers to the variability among living organisms (animals, plants, and microorganisms) including inter alia, terrestrial, marine, and other aquatic ecosystems with their ecological complexes. In another expression, biodiversity encompasses the variety and variability of all forms of life on earth that play a great role in human existence $[1,2]$. It also includes the ethnical value of biodiversity such as tradition and traditional knowledge of the indigenous and local communities [2] and the diversity within species (genetics), between species and of ecosystems [3].

Genetic diversity refers to the variation within species of any plant, animal or microbes in the functional units of heredity. Species diversity refers to the variety of species within a geographical area, which become central in the evaluation of diversity, and used as a point of reference in biodiversity conservation. Finally, ecosystem diversity refers to the variety of life forms in a given territory or area with all its functional ecological processes, which is often evaluated based on the diversity of all of its components [1].

Biodiversity is important for the maintenance of a healthy environment and used for direct human benefits like food, medicine, and energy. It is also used for recycling of different essential elements, for mitigation of pollution, for protection of watersheds, to mitigate soil erosion and to control excessive variations in climate and catastrophic events. For example, biodiversity provides different services free of charge worth of billions dollar every year for crucial well-being of the society. Some of these services are providing clean water and air, soil formation and protection, pollination, pest control, food, fuel, fibers, medicine, and construction and industry raw materials [4]. Agricultural biodiversity is another important component of biodiversity, which has a more direct link to the well-being and livelihood of mankind than other forms of biodiversity. Food plant and animal species have been collected, used, domesticated, and improved through traditional systems of selection over many generations [5]. 
However, today much of the lines of evidences are increasingly pointing out a significant global decline in biodiversity by numerous, varied, and interacting drivers [6]. More than half of the habitable surface of the earth has already been significantly altered by human activities. As a consequence, biodiversity of our planet is on the verge of decline and extinction despite our limited and incomplete knowledge on them [7]. Biodiversity loss and extinction processes can occur in two phases. The first phase is known as deterministic and often resulted from human threats such as habitat loss, fragmentation and degradation, direct exploitation of the species, competition from exotic and domestic species, and persecution and killing due to human animal conflicts. The second phase is known as deterministic that resulted from failures in mitigating threats that eventually result in very small, fragmented, and isolated remnant populations. Then these small remnant populations become vulnerable to a number of other, nonhuman caused threats mainly stochastic, genetic (genetic drift and inbreeding), and demographic events [8]. Thus, small, fragmented, isolated populations can find themselves being dragged into an extinction vortex whereby genetic and demographic stochastic events can cause the species to go extinct. During this second phase of the extinction process, very intensive management of populations and individuals is often necessary to prevent extinction [9].

Several human induced impacts are leading to a mass extinction process affecting global biodiversity. The major reasons for rapid diminishing of biodiversity are attributed to conversion of land for agriculture, wild fires, poor management of available land, over-exploitation for food, fuel-wood, medicine, construction, overgrazing by cattle, displacement and loss of landraces, lower yielding varieties, pests and diseases, global climate change, pollution (e.g., acid rain), and gap of scientific knowledge on some of the biological resources $[1,7,10]$. Human beings are destroying biodiversity, particularly during livelihood activities with or without knowledge of the consequences of their actions [6]. Agriculture is one of the most important land-use that results in detrimental environmental consequences from increased use of fertilizers and biocides, land draining, irrigation, and the loss of many biodiversity-rich landscape features [6]. There are many threats to biodiversity as a result of agricultural practice through changes in land-use, replacement of traditional varieties by modern cultivars, agricultural intensification, increased population, poverty, land degradation, and environmental changes (including climate change) [5]. Recent estimates indicate that humans use more than $40 \%$ of the terrestrial components and significantly modified global biodiversity [7]. As a consequence, many species of living organisms are classified as threatened today and this has become a central concern for conservation [11].

Conserving biodiversity has economic, social, and cultural values. Conservation of biodiversity is integral to the biological and cultural inheritance of many people and the critical components of healthy ecosystems that are used to support economic and social developments. Moreover, it is used to maintain the earth's genetic library from which society has derived the basis of its agriculture and medicine $[5,12]$. The twenty-first century is predicted to be an era of bioeconomy driven by advances of bioscience and biotechnology. Bio-economy may become the fourth economy form after agricultural, industrial, and information technology economies, having far-reaching impacts on sustainable development in agriculture, forestry, environmental protection, industry, food supply, health care and other micro-economy aspects. Thus, a strategic vision for conservation and sustainable use of biodiversity in the 21st century is of far-reaching significance for sustainable development economy and society [13].

Biodiversity conservation refers to the management of human use of biodiversity in order to get the greatest sustainable benefit to present and future generations. Thus, conservation of biodiversity embraces the protection, maintenance, sustainable utilization, restoration, and enhancement of biodiversity [1]. Biodiversity conservation mainly focuses on genetic conservation with its diverse life-support systems (ecosystems) for the connotation of human well-being [3].

Conservation techniques can be grouped into two basic, complementary strategies: in situ and ex situ [14]. As also outlined in the articles 8 and 9 of the Convention of Biological Diversity (CBD), biodiversity is conserved by two major methods called in situ and ex situ. The conservation efforts, either in situ or ex situ, involve the establishment and management of protected areas and relevant research institutes or academic institutions, which establish and manage arboreta, botanical or zoological gardens, tissue culture, and gene banks [1]. The concept of ex situ conservation is fundamentally different from that of in situ conservation; however, both are important complementary methods for conservation of biodiversity. The principal difference (and hence the reason for the complementarities) between the two lies in the fact that ex situ conservation implies the maintenance of genetic materials outside of the "normal" environment where the species has evolved and aims to maintain the genetic integrity of the material at the time of collection, whereas in situ conservation (maintenance of viable populations in their natural surroundings) is a dynamic system, which allows the biological resources to evolve and change over time through natural or human-driven selection processes [5].

In situ conservation is defined as conservation of ecosystems and natural habitats, the maintenance of viable populations of the species in their natural surroundings and, in the case of the cultivated species, in the surroundings where they have developed their distinctive properties. In situ conservation can be done in farmers' fields, in pasture lands, and in protected areas [15]. For cultivated species, in situ conservation concerns the maintenance of the local intra- and inter-population diversity available in various ecological and geographical sites $[1,16]$. Thus, it allows ongoing host-parasite coevolution, which is likely to provide material resistance to pests and diseases, and CBD recognized it as a primary approach to conserve biodiversity [4]. However, in situ conservation has certain limitations like more difficult access to breeders requiring the application of its complimentary technique. For example, some of the natural habitats or wild habitats are very risky when compared to relatively safe captive environment [9]. 
The second biodiversity conservation technique receiving the most attention to conserve biodiversity is ex situ. Ex situ conservation techniques are mostly used to be applied to species with one or some of the following characteristics: endangered species, species with a past, present or future local importance, species of ethno-botanical interest, species of interest for the restoration of local ecosystems, symbolic local species, taxonomically isolated species, and monotypic or oligotypic genera [17]. Intensive conservation and management of populations and individuals can come in many different forms, like translocation, breeding in a fenced wild habitat, supplementary feeding, captive hand rearing of young of wild parents to become pregnant sooner, and captive breeding [9].

\section{Ex Situ Conservation}

Ex situ conservation is a technique of conservation of biological diversity outside its natural habitats, targeting all levels of biodiversity such as genetic, species, and ecosystems $[1,2,16]$. Its concept was developed earlier before its official adoption under the Convention on Biological Diversity signed in 1992 in Rio de Janeiro [2]. In general, ex situ conservation is applied as an additional measure to supplement in situ conservation, which refers to conservation of biological diversity in its natural habitats [16]. In some cases, ex situ management will be central to a conservation strategy and in others it will be of secondary importance [18]. Broadly, ex situ conservation includes a variety of activities, from managing captive populations, education and raising awareness, supporting research initiatives and collaborating with in situ efforts [19]. It is used as valuable tools in studying and conserving biological resources (plants, animals, and microorganisms) for different purposes [2] through different techniques such as zoos, captive breeding, aquarium, botanical gardens, and gene banks [16].

\subsection{Types of Ex Situ Conservation}

2.1.1. Zoos. Zoos or zoological gardens or zoological parks in which animals are confined within enclosures or seminatural and open areas, displayed to the public, and in which they may also breed. They are considered by universal thinkers and environmentalists as important means of conserving biodiversity [19-21]. Zoos attract as many as 450 million visitors each year and so are uniquely placed to have very large educational and economic values [22]. Zoos not only act as places of entertainment and observing animal behavior, but are also as institutions, museums, research laboratories, and information banks of rare animals [23]. Although some people dislike zoos, many people enjoy them. Over the last several decades, zoos have made significant progress in its cooperative management of ex situ populations of a variety of biodiversity [9].

Zoos breed many endangered species to increase their numbers. Such captive breeding in zoos has helped to save several species from extinction [19]. Management of animals in zoos includes animal identification, housing, husbandry, health, nutrition as well as addressing and ways of interaction with the public [20]. There are various processes and mechanisms used to determine whether a species or taxon is included within a zoo's collection plan. The frequently used criteria include how the species is valued, according to its uniqueness, contribution to research or education, and conservation status [19]. Zoos help the animal to secure food, shelter, social contact and mates, and to be motivated by desire (appetitive behavior), which is reinforced by pleasure (consummative behavior) [21].

In the past, some zoos paid little attention to the welfare of the animals, and some zoos today have poor environments for animals [24]. They were also once reliant on harvest from the wild to populate their exhibits and reliance on continued wild collection to breeding closed populations [23]. Many zoo animals also became endangered or extinct due to visitor disturbances, unfavorable climate and due to insufficient space [20]. From this aspect, many scholars state on the negative features of keeping animals in zoo as it causes pain, stress, distress, sufferings and evolutionary impacts [21]. Animal welfare, education, conservation, research, and entertainment are major goals of modern zoos, but these can be in conflict. For example, visitors enjoy learning about and observing behavior in captive animals, but visitors often want to observe and interact with the animals in close proximity. Unfortunately, proximity to and interactions with humans induce stress for many species [25]. The same is true for Addis Ababa Lion Zoo Park.

However, progressive zoos are engaged in education, research, and conservation, with the aim of maintaining healthy animals, which behave as if they are in their natural habitats [24]. The current paradigm for managing essential populations is to minimize the rate of genetic decay, slow adaptation to the captive environment, and retain typical behaviors $[23,26]$. It is widely accepted that the more generations a population spends in captive breeding, the less suitable it is for attempted restorations in the wild. Hence, population management is designed not to deplete too quickly the resource obtained from the founders [23]. Thus, for true sustainability of the species for the purpose of conservation, display, education, and research, constant refreshing of populations is required $[9,23]$. Majority of the current breeding programs base on the genetic management of populations by the analysis of individual pedigrees in order to minimize kinship [9].

2.1.2. Captive Breeding. Captive breeding is an integral part of the overall conservation action plan for a species that helps to prevent extinction of species, subspecies, or population. It is an intensive management practice for threatened individuals, populations, and species by anthropogenic and natural factors [9]. In small and fragmented populations, even if the human caused threats could be magically reversed, the species would still have a high probability of extinction by random demographic and genetic events, environmental variations, and catastrophes. Thus, under sufficient knowledge on the biology and husbandry of the species, captive breeding helps individuals in the relative safety of captivity, under 
expert care and sound management by providing an insurance against extinction [9]. Stock for reintroduction or reinforcement efforts, opportunities for education, raising of awareness, scientific and husbandry research, and other contributions to conservation are also possible through captive breeding $[9,27]$.

Environmental enrichment strategies are used to improve both physiological and psychological welfares of captive animals, which can be achieved by increasing the expression of natural behavior and decreasing abnormal behaviors. Successful environmental enrichment includes the improvement of enclosure design and the provision of feeding devices, novel objects, appropriate social groupings, and other sensory stimuli [27]. The minimum requirement for successful ex situ management, particularly in the captive populations, is the inclusion of as much of the genetic diversity present in wild populations. Genetic sustainability (retention of $90 \%$ of the gentic diversity of the wild population for 100 years) in captive breeding is maintained if consideration is given on number of founders, population growth rate, effective population size, and duration of the captive program [19]. However, even if at least 30 founders in captive breeding are recommended to ensure the representation of large enough proportion of the genetic diversity of the wild population, for critically endangered species, actively removing individuals from the wild population to serve as founders may compromise the survival of the wild population [9]. For example, the Arabian Oryx captive breeding program was based on fewer founders and grew to a couple of thousand individuals through breeding management, which helped to reduce risks.

However, there are several challenges (biological and envi ronmental) that are limiting factors to the attainment of the goal of captive breeding for many species [19]. One of the major challenges is a circular consequence of smallpopulation management that has inherent genetic and demographic problems due to genetic diversity loss and demographic stochasticity [19]. In addition, individuals that are well adapted to the circumstances in captivity may also be less well adapted to the circumstances in the wild and may show lower fitness upon reintroduction [28]. Most notably, within the captive environment, housing and husbandry will also have significant impacts on birth and death rates [19].

2.1.3. Aquarium. An aquarium is an artificial habitat for water-dwelling animals. It can also be used to house amphibians or large marine mammals and plant species for tourist attractions. It is usually found in zoos or marine parks with different size. The 15,750 described species of freshwater fish comprise around $25 \%$ of living vertebrate species diversity and a key for global economic and nutritional resources of which more than $11 \%$ is threatened (60-extinct, 8 -extinct in the wild and 1679-threatened) [22]. Fresh waters $(0.3 \%)$ of available global surface water support $47-53 \%$ of all extant fish species that are threatened by overfishing, pollution, habitat loss, damming, alien invasive species, and climate change. This requires world's zoos and aquariums to identify the potential targets (species or areas) for in situ and ex situ conservation program $[18,22]$. Aquarium is used to admire at home by hobbyists, to portray as public exhibits, to provide large quantities of human food and animal fodder [18].

Fishes are often overlooked within the development of conservation priorities. This leads to the low focus on meaningful conservation efforts rather than giving more attention for their importance to food supply and livelihoods. For example, it provides job opportunity for over 60 million people, as source of food for over 200 million people in Africa, for US\$1.5 billion income from trade of 4000 species global ornamental fish industry, and many are displayed in the world's public zoos and aquaria to a global audience of as many as 450 million people per year [22, 29]. However, despite the clear value of freshwater fish diversity, wetland habitats and their associated freshwater-fish species continue to be lost or degraded at an alarming rate [30]. One recommendation is for aquariums to set up sustainable breeding program that prioritizes threatened species (VU, EN, and CR) and those classified as EW to support species conservation in situ and aid the recovery of species via collaborative reintroduction or translocation efforts when appropriate [22].

2.1.4. Botanical Gardens. Botanical gardens consist of living plants, grown out of doors or under glass in greenhouses and conservatories. They are used to grow and display plants primarily for scientific and educational purposes. They also include herbarium, lecture rooms, laboratories, libraries, museum and experimental or research plantings. It can be taxonomic collection of a particular family, genus or group of cultivars, native plants, wild relatives, medicinal, aromatic, or textile plants [4]. There are over 2,000 botanic gardens, holding 80,000 plant species in their living collections and receiving hundreds of millions of visitors per annum [14, 31]. Furthermore, they have valuable and distinctive mix of officials dedicated to plant research, systematics, conservation education, and public awareness [31]. They are now extremely well networked both among themselves and with other professionals, conservation organizations, and nongovernmental organizations (NGOs) [31]. They provide different services for sectors that utilize and conserve plant diversity like agriculture, forestry, pharmaceutical and biofuel industries, protected area management, and ecotourism. They have a unique opportunity as visitor attraction places and scientific institutions for documentation and conservation of plant diversity by shaping and mobilizing citizens to the current environmental challenges [31]. They also play a great role in attaining target of the Global Strategy for Plant Conservation for 2020 to cultivate $75 \%$ of the world's threatened plant species in ex situ [14]. Botanical gardens give opportunity for arable plants to be grown under relatively modified environmental conditions (intense cultivation, relatively high fertility, and high levels of disturbance) [14].

However, most of the cultivated taxa are held in a small number of collections and mostly only in small populations. Lack of genetic exchange and stochastic processes in small populations make them susceptible to detrimental genetic effects [14]. The low number of ex situ populations in most botanical gardens poses a fundamental problem for conservation. The total ex situ breeding collection is therefore very 
small with respect to the stated aim of conserving regional gene pools [14]. The striking lack of information on source populations casts doubt on the value of using such ex situ populations for potential reintroductions. They also require testing for fitness and similarity to wild populations before they are brought to the field [14]. Thus, conservation actions of botanic gardens such as training and capacity building, needs to be better understood and better coordinated [31].

2.1.5. Gene Banks. Genome resource banking is another management technique used for biodiversity conservation. Different types of gene banks have been established for the storage of biodiversity, depending on the type of materials conserved. These include seed banks (for seeds), field gene banks (for live plants), in vitro gene banks (for plant tissues and cells), pollen, chromosome, and deoxyribonucleic acid (DNA) banks for animals (living sperm, eggs, embryos, tissues, chromosomes, and DNA) that are held in short term or long term laboratory storage; usually cryopreserved or freeze-dried [32]. Currently, there are about 7.4 million PGRFA accessions conserved in over 1750 gene banks [5]. The Genome 10K (G10K) project aims to sequence the genomes of 10,000 vertebrates, of which 4,000 will be fish. To date, 60 fish genomes have been sequenced in laboratories worldwide and added to the database, and a further 100 are targeted. The Frozen Ark database holds details of 28,060 frozen DNA samples. Among these 6,997 are from species listed in the IUCN Red List [18]. The principal aim of gene bank conservation is to maintain genetic diversity alive as long as possible and to reduce the frequency of regeneration that may cause the loss of genetic diversity [5].

With the rapid development in the field of molecular genetics and genomics, DNA is becoming more and more in demand for molecular studies and is one of the most requested materials from gene banks. Establishing DNA storage facility as a complementary "backup" to traditional ex situ collections has been suggested [5]. Some efforts have been made to establish DNA banks for endangered animals [33], and a few plant DNA banks in different parts of the world such as the Missouri Botanic Garden, Kew Royal Botanic Garden and Australian Plant DNA Bank. Many research groups are already developing their own archives of extracted genomic DNA. Recently, the Global Biodiversity Information Facility in Germany has established a DNA bank network, which provides DNA samples of complementary collections (microorganisms, protists, plants, algae, fungi, and animals) [5].

Seeds are usually the most convenient and easiest material to collect and to maintain in a viable state for long periods of time and that makes it preferred for conservation in gene banks [14,34]. Seed banking techniques rely on the storage of dried seeds of threatened or other plants at low temperatures as the most important factors influencing seed longevity are temperature, seed moisture content, and relative humidity $[14,35,36]$. Seeds are typically conserved at moisture content between 3 and 7 percent and stored at 4 degrees Celsius for short-term conservation, and between -18 and -20 degrees Celsius for long-term conservation [5, 34]. Current research is showing that there exists variability in seed longevity for different species being conserved under similar conditions. In addition, it has been found that the type of seed (endospermic or non-endospermic) and intraspecific variation may also affect accessions longevity [5]. In addition, high initial quality seeds are a major prerequisite for ensuring seed longevity in seed banks [5].

Plants that cannot be conserved as seeds because of their recalcitrant nature (i.e. seeds that are desiccation and/or cold sensitive) or are clonally propagated are traditionally conserved as live plants in ex situ field gene banks. But, field gene banks present real logistical challenges; they require large areas and are costly, they are vulnerable to pests and diseases, natural disasters, political unrest, extreme weather, fire, vandalism, and theft, and they often are at risk due to policy changes on land use [5].

In vitro conservation refers to one type of gene bank known as slow-growth conservation method. It involves culturing of different parts of the plant (meristem, tissues, and cells) into pathogen-free sterile culture in a synthetic medium with growth retardants, which has been cited as a good way of complementing and providing backup to field collections [5].

The other genome conservation technique is cryopreservation, in which living tissues are conserved at very low temperatures $\left(-196^{\circ} \mathrm{C}\right)$ in liquid nitrogen to arrest mitotic and metabolic activities [5]. It is now realized that cryopreservation method can offer greater security for long-term, cost effective conservation of plant genetic resources, including orthodox seeds [5]. The storage in liquid nitrogen clearly prolonged shelf life of lettuce seeds with half-lives projected as 500 and 3400 years for fresh lettuce seeds stored in the vapor and liquid phases of liquid nitrogen, respectively [5].

2.2. Advantages of Ex Situ Conservation. It is generally preferred to conserve threatened species in situ, because evolutionary processes are more likely to remain dynamic in natural habitats $[14,19]$. However, considering the rate of habitat loss worldwide, ex situ cultivation is becoming increasingly important [14]. Further more, as many of the taxa are located outside natural parks or reserves, in situ measures are not enough to assure their conservation. Translocation, introduction, reintroduction, and assisted migrations are species conservation strategies that are attracting increasing attention, especially in the face of climate change [37].

As approximately 450 million people per year visit zoos and aquaria globally, their education and marketing services play a key role in communicating the issues, raising awareness, changing behavior, and gaining widespread public and political support for conservation actions. Zoos support conservation by educating the public, raising money for conservation programs, developing technology that can be used to track wild populations, conducting scientific research, advancing veterinary medicine, and developing animal handling techniques [22]. By studying animals in captivity and applying that knowledge to their husbandry, zoos can provide valuable and practical information that may be difficult or impossible to gather from the wild [24]. Zoos 
and aquaria have significant roles to play in improveing public awareness of the issue facing species and their habitats; for example, through presentation of maps and photographs of species recently extinct as a result of anthropogenic impacts. A similar display of threatened species, even if not currently in the collections of the zoo, would help convey to the public the magnitude of the threat facing the species $[18,22]$. It also reaches a wide cross-section of the society, because zoo audiences are not limited to those who are already passionately interested in wildlife and because many zoo visitors are children. Some of these children may become committed conservationists. Some may grow up to be oil company tycoons, politicians, or movie stars, with great potential influence. Some may even live next door to a poacher or wildlife dealer. Thus, instilling an interest in conservation of wildlife in people from all walks of life while they are young is one vital role zoos can play [38]. It is often claimed that zoos perform valuable conservation work by breeding endangered species and returning them to the wild. Zoos can also be used for businesses that make money. This means that animals are often bred for commercial purposes because the public like to see new-born animals. Such breeding leads to a surplus of animals, and in order to keep numbers down sold to private collectors, circuses, or even research laboratories. A zoo with good and attractive entertainments encourages initial visits and subsequent returns to the zoo, which is used to get more revenue for conservation efforts, research, and general animal care and welfare and also to develop more positive perceptions of animals in zoos and become more supportive of conservation efforts $[25,39]$.

2.3. Disadvantages of Ex Situ Conservation. Some ex situ conserved collections showed lower resistance levels, although still others showed higher resistance levels than their in situ conserved counterparts mainly due to the high evolutionary drive and complex nature of evolutionary scenario [40].

The behavior of animals in the zoo may be affected by the frequent arrival of large number of people, who are unfamiliar to the animals [41]. Animals housed in artificial habitats are confronted by a wide range of potentially offensive environmental challenges such as artificial lighting, exposure to loud or aversive sound, arousing odors, and uncomfortable temperatures or substrates. In addition, confinement-specific stressors such as restricted movement, reduced retreat space, forced proximity to humans, reduced feeding opportunities, maintenance in abnormal social groups, and other restrictions of behavioral opportunity are considered [42]. However, over the course of the twentieth century, as knowledge of wildlife biology improved, zoo animals began to be kept in more natural surroundings and social groupings, and diets and veterinary care began to improve. Thus, survival and breeding rates of captive populations improved [38]. Evidence mainly from studies of rodents and primates strongly indicates that prenatal stress can impair stress-coping ability and is able to cause a disruption of behavior in aversive or conflict-inducing situations. Prenatally stressed animals show retarded motor development, reduced exploratory and play behavior, and impairments of learning ability, social behavior, and sexual and maternal behavior. Prenatal stress may also affect the sex ratio at birth and the reproductive success [43].

Although populations of some species managed in ex situ may have the best hope for their long-term survival, they might be challenged if not properly managed during translocation and reintroduction with the effects of climate change [22]. Some species may lose their biological integrity particularly on morphology. For example, an experimental study on black-footed ferrets (Mustela nigripes) in ex situ indicated a decrease of $5-10 \%$ body size than pre-captive, in situ animals [44]. In other words, the small cage size and environmental homogeneity inhibit mechanical stimuli necessary for long bone development. Thus, in the absence of such an environment, "unnatural" morphologies can result that may contribute to poor fitness or perhaps even for domestication and reintroduction and relocation [44]. It would be very difficult to reintroduce some zoo-reared animals to their natural habitats because, after generations of captivity, many have lost the necessary skills to survive in their original habitats [22].

For naturally out-breeding species, the high levels of inbreeding in captivity often have negative effects on life history traits related to reproduction and survival [11]. It makes the population in captivity deteriorate due to loss of genetic diversity, inbreeding depression, genetic adaptations to captivity, and accumulation of deleterious alleles [17]. For plants, ecological shifts, small population size, genetic drift, inbreeding, and gardener-induced selection may negatively affect population structure after several generations of ex situ cultivation $[16,45,46]$. These factors could seriously put at risk the success of ex situ conservation [17].

Captive breeding of threatened species has used increasingly sophisticated technologies and protocols in recent years [47]. Although, this has blurred the dichotomy between in situ and ex situ species management, the value of captive breeding as a conservation tool remains controversial [48]. It is recognized that ex situ conservation has many constraints in terms of personnel, costs, and reliance on electric power sources (especially in many developing countries where electricity power can be unreliable) for gene banks. It requires high facilities and financial investments. It cannot also conserve all of the thousands of plant and animal species that make up complex ecosystems such as tropical rainforests [49]. Capture of individuals from the wild for captive breeding or translocation some times can have detrimental effects on the survival prospects of the species as a whole through disease infection [50].

Even though the management of irreplaceable animal populations in zoos and aquarium has focused primarily on minimizing genetic decay with the use of advanced technologies, recent analyses have shown that as most zoo programs are not projected to meet the stated goals due to lack of achieving "sustainability" of the populations [23]. Thus, managing zoo populations as comprehensive conservation strategies for the species requires research on determinants of various kinds of genetic, physiological, behavioral, and morphological variations, and their roles in population viability, 
development of an array of management techniques, tools, and training of managers [23].

2.4. Challenges to Ex Situ Conservation. Ex situ conservation requires different kinds and levels of intensity of management, and a multistakeholder approach like the input from experts on aquarium and zoo husbandry, ex situ breeding, gene-banking, reintroduction, and habitat restoration [51]. Other expert input may include taxonomy, ecology and conservation, ethnography, and sociology. For outreach program, there is a need to liaise with local communities and national government fisheries and wildlife departments; with international (nongovernmental and intergovernmental) conservation bodies [18].

The most important challenges of applying ex situ conservation (captive breading) are the difficulty in recognizing the right time, identifying the precise role of the conservation efforts within the overall conservation action plan, and setting realistic targets in terms of required time span, population size, founder numbers, resources, insurance of sound management and cooperation, and the development of much needed new technical methods and tools [9]. In captive breeding to achieve the retention of $90 \%$ of the wild gentic diversity, it is necessary to incorporate sufficient number of founders, careful pair combinations and management [9]. Evidence also exists, which demonstrates that manipulation of housing and husbandry variables can also have significant positive influence on animal reproduction in captivity [19].

In many cases, ex situ populations are founded from only a few individuals, which cause genetic bottlenecks. Small populations are exposed to threats such as stochastic demographic events as well as genetic effects, including loss of genetic diversity, inbreeding depression or accumulation of new, potentially deleterious mutations [11]. More specific problems in garden populations include poorly documented or even unknown sources of material, accidental hybridization of material from various localities, and or unintended selection for traits more suited to garden conditions [14]. In every region, most of the cooperatively managed breeding programs have too few animals, too few animals in appropriate situations for breeding, too few successful breeders, too few founders, and too many animals with undocumented ancestries and/or too little cooperation with scientifically designated breeding recommendations. These deficiencies are resulting in declining populations or declining gentic diversity or both $[23,52]$.

Problems associated with small founder populations such as inbreeding depression, removal of natural selection, and rapid adaptation to captivity pose considerable challenges for managers of captive populations of threatened species [48]. Equally, reintroduction of captive-bred stock to the wild may require implementation of rigorous protocols that embrace acclimation, pre- and post-release training, health screening, genetic management, long-term monitoring, and involvement of local stakeholders [53, 54]. Shortfalls in implementing such protocols may jeopardize the likelihood of achieving success [47].

Inbreeding due to the mating between two related individuals is unavoidable in small, fragmented, or isolated pop- ulations typical of many threatened species, and it can lead to a significant reduction in fitness. The deleterious effects of inbreeding on individual fitness can be large and may be an important factor contributing to population extinction. Inbreeding depression has potential significance for the management and conservation of endangered species [55]. As populations get smaller, the probability increases for all offspring in a given generation are of the same sex [19].

Evaluating the long-term efficiency of ex situ conservation is important, but is complicated because of the difficulty of finding more than one sample of a documented (origin and cultivation) ex situ population and its corresponding stillexisting in situ source population [46].

Animal translocations are usually risky and expensive, and a number of biological and nonbiological factors can influence success. Biological considerations include knowledge of genetics, demography, behavior, disease, and habitat requirements. It also includes legal framework, fiscal and intellectual resources, monitoring capacity, goal of the translocation, logistic challenges, and organizational structure of decision making [56].

The regeneration process is one of the most critical steps and a major challenge in gene bank management, during which there is the highest probability for genetic erosion [57]. It is equally important to understand how different conservation methods (seed, field, and cryopreservation) and their management can affect or change the genetic make up, thereby reducing the effective population size $(\mathrm{Ne})$. This will also contribute to decision-making process for determining which methods to use for conservation of the wide diversity [5].

If people are discouraged or prevented from interacting with the resident animals, fewer visitors attend, decreasing public financial support. The visitors' noise and crowding become a source of stress for many species that affects both their welfare and the enjoyment of the visitor [25].

\section{Ex Situ Conservation Practice in Ethiopia}

Ethiopia is considered to be one of the richest centers of genetic resources in the world. It is believed that indigenous crops such as teff (Eragrostis tef), Noug (Guizotia abyssinica), and Enset (Ensete ventricosum) were first domesticated in Ethiopia. Numerous major crop species including durum wheat (Triticum durum), barley (Hordeum vulgare), sorghum (Sorghum bicolor), sesame (Sesamum indicum), castor (Ricinus communis), and coffee (Coffea arabica) are also known to show significant diversity in the Ethiopian region [58]. Almost $85 \%$ of the populations of Ethiopia live in rural areas and most of this population depends directly or indirectly on biodiversity. Biodiversity also plays a crucial role in the different sectors like energy, agriculture, forestry, fisheries, wildlife, industry, health, tourism, commerce, irrigation, and power [15].

The records on biodiversity conservation efforts in Ethiopia date back to the days of Emperor Zera-Yakob (14341468 E.C.). The Emperor brought juniper seedlings from Wof Washa of North Shewa and planted in Managesha-Suba area. 
Modern conservation intervention began by Emperor Menilik in 1908 E.C. and eventually evolved to the establishment of protected areas in the 1960s [4]. Currently, a number of stakeholders are actively working on biodiversity related issues at the federal government level. These include Institute of Biodiversity Conservation (IBC), Ethiopian Institute of Agricultural Research (EIAR), Ethiopian Wildlife Conservation Authority (EWCA), Ministry of Agriculture and Rural Development (MoARD), Ministry of Science and Technology (MoST), Higher Learning Institutions (HLIs), particularly Addis Ababa University (AAU), and offices in various regional states of Ethiopia [59]. Ex situ conservation as complementary to the rehabilitation and restoration of degraded ecosystems and the recovery of threatened species was started 1976 with the establishment of IBC [4].

Ex situ conservation activities mostly focus on high socioeconomic value and internationally important crop types that are considered to be facing immediate danger of genetic erosion [15]. The collections held at IBC are mostly of indigenous landraces some of which are not seen today in farmlands. The collections of root crops, medicinal plants, weedy species, and wild relatives of cultivated species are still relatively inadequate within the existing ex situ collections [60]. However, appropriate emphasis is being placed on conservation and sustainable use of all forms of plant biological resources [60]. Since the establishment of IBC, systematic crop germplasm exploration and collection operations have been undertaken in the different administrative regions of the country, covering a wide range of agroecological zones. Collection priorities were set based on factors like economic importance, degree of genetic erosion and diversity, researchers' needs, the rate of diffusion of improved varieties, clearing of natural vegetation, agricultural policies, natural disasters, and resettlement program [4].

Currently about 68,014 seed accessions of 200 plant species, 6,704 accessions of 205 species of forestry, medicinal, forage and pasture plants (in field gene bank), 290 species of microbial genetic resources, and three semen of threatened breed of domestic animals are conserved by IBC. About $90 \%$ of the total germplasm holdings in the gene bank consist of field crops. The total collection is composed of cereal seeds, pulses, oil crops, spices, and species of medicinal and industrial value. Aside from the crop collections, the gene bank also holds 650 collections of micro-organisms. Over 9,000 accessions of horticultural crops, medicinal plants, and herbs are maintained in field gene banks. The type and nature of collection missions and number and lists of plant species and landraces collected have been documented in manuals and reports. Regular monitoring activities are performed for seed viability [15].

For plant species with recalcitrant and intermediate storage behavior, there are ten field gene banks under IBC control and small sized fields in the various research stations of the Ethiopian Institute of Agricultural Research (EIAR) and at universities. The plan for the immediate future is to increase the number of field gene banks in different agroecological zones. Community gardens, backyards, and holy places are being considered for inclusion in the future plan. Spices, vegetables and medicinal plants require management on a large scale and with the full involvement of the local communities [15]. The initiative at national level is still in its infancy and there is currently no well-established national botanical garden in Ethiopia including the Gulele Botanical Garden Center [4, 59]. The Gulele Botanic Garden Center was established through the Proclamation No. 18/2005 E.C. in October 30/2002 E.C. in a 705 hectare land at Gulele and Kolfe-Kernayo subcities. It was established with a vision to see the center to be developed as an exemplary garden in terms of education, ecotourism attraction and center for originality of the Ethiopian plant species, and to be a place of research and nurturing of plant species. The center also has a mission to provide persistent ecotourism services to tourists by taking care of plant species and carrying out educational and research works [59].

Although there is no well-established zoo or zoological garden in Ethiopia, the Addis Ababa Lion Zoo Park can be dominantly cited [59]. The Addis Ababa Lion Zoo Park was established in 1948 with five founder lions presented to Emperor Haile Selassie as gifts. The park accommodates lions with cubs, tortoises, baboons, monkeys, apes, and ducks. A team of international researchers has provided the first comprehensive DNA evidence from 15 (eight males and seven females) samples of Addis Ababa lion indicating the genetically unique samples that requires immediate conservation action. Both microsatellite and mitochondrial DNA data suggest that the zoo lions are genetically distinct from all existing lion populations for which comparative data exist.

Desiccation-intolerant seeds and species that do not readily produce seeds are conserved ex situ in field gene banks. For example, accessions of coffee (Coffea arabica), root crops such as yam (Dioscorea bulbifera) and "Oromo dinich" (Coleus edulis), and spices like ginger (Zingiber officinale) and Ethiopian cardamom (Aframomum corrorima) are conserved in agro-ecological zones in field gene banks [60].

The need for action for global biodiversity conservation is now well understood, and government agencies, nongovernmental organizations, and botanic gardens have all been working in various ways to promote environmental sustainability and reduce species and habitat loss [31].

Seed banking is the major ex situ conservation method employed in Ethiopia. There are three major seed banks operating in Ethiopia. The National Tree Seed Project processes seeds from a narrow range of tree species and uses shortterm storage facilities. It aims to cater for the annual seed demand from commercial and small-scale forestry enterprises. Of the 70 species regularly collected and processed, 20 are indigenous. The Forage Genetic Resources Centre maintained by the Consultative Group on International Agricultural Research at the International Livestock Research Institute maintains long-term conservation of a wide range of native and exotic forage species. The Institute for Biodiversity Conservation and Research holds active collections of seeds mainly for research and distribution and as a base collection for long-term conservation [60].

For security reasons, the collected and stored germplasm need to be conserved in duplicate gene banks. However, except for the limited samples of the Ethiopian germplasm held by the Consultative Group on International Agricultural 
Research, United States Agency for International Development, and the Nordic Gene Bank, majority of the Ethiopian collections are still kept in a single copy at the National Gene Bank. Greater efforts need to be made to store duplicate collections to avoid future genetic erosion [15]. For the continuing power supply, the Ethiopian Gene Bank has independent power supply in the form of a stand by generator to overcome power cuts [15].

Lack of adequate knowledge with respect to collection, handling, and treatment of seeds often impedes the planting of indigenous trees and shrubs. Inadequate work has been done on establishing the seed storage behavior of native species resulting in only limited availability of ex situ conservation seed collections especially with respect to native forest species [60] and lack of alternative storage facilities for the existing conventional cold rooms (e.g., in vitro and cryopreservation methods) [4]. The current holdings of the IBC gene bank reach over 60,000 accessions of plant species. Some collections are in the medium-term storage mainly due to insufficient seed samples [15].

\section{Conclusion}

Biodiversity plays a great role in human existence and in healthy function of natural systems although it is on the way of depletion dominantly due to anthropogenic activities. This requires conservation of biodiversity either in in situ or ex situ or both methods in combination based on the conservation situation and its objective. Although in situ conservation is more encouraged to be used for biodiversity conservation, ex situ conservation is recommended as it complements through different techniques like zoo, captive breeding, aquarium, botanical garden, and gene bank. Ex situ conservation has its own advantages, disadvantages, and challenges making decision on its application by evaluating advantages, disadvantages and challenges. Although, Ethiopia is rich in biodiversity resources, more people depend on it for their livelihood directly or indirectly causing a great loss. Even if the conservation of biodiversity in Ethiopia has long-time history, its progress, coverage, and enforcement of the rule for conservation seem to be weak. Despite of good progress made in gene bank conservation, it is yet to be developed. In the same way, attention should be given for developing a National Zoological Park and a Botanical Garden.

\section{Acknowledgments}

The authors are extremely grateful to Dr. Habte Jebessa for his valuable comments, suggestions and corrections on the draft of this paper. Our appreciation also goes to Professor. Afework Bekele for his remarkable encouragements and critical comments on the draft of this paper.

\section{References}

[1] T. I. Borokini, A. U. Okere, A. O. Giwa, B. O. Daramola, and W. T. Odofin, "Biodiversity and conservation of plant genetic resources in Field Gene-bank of the National Centre for Genetic Resources and Biotechnology, Ibadan, Nigeria," The
International Journal of Biodiversity and Conservation, vol. 2, pp. 37-50, 2010.

[2] M. Antofie, "Current political commitments' challenges for ex situ conservation of plant genetic resources for food and agriculture," Analele Universităţii din Oradea-Fascicula Biologie, vol. 18, pp. 157-163, 2011.

[3] C. A. Tisdell, "Core issues in the economics of biodiversity conservation," Annals of the New York Academy of Sciences, vol. 1219, no. 1, pp. 99-112, 2011.

[4] Institute of Biodiversity Conservation, National Biodiversity Strategy and Action Plan, Institute of Biodiversity Conservation, Federal Democratic Republic of Ethiopia, Addis Ababa, Ethiopia, 2005.

[5] M. E. Dulloo, D. Hunter, and T. Borelli, "Ex situ and in situ conservation of agricultural biodiversity: major advances and research needs," Notulae Botanicae Horti Agrobotanici ClujNapoca, vol. 38, no. 2, pp. 123-135, 2010.

[6] J. Young, C. Richards, A. Fischer et al., "Conflicts between biodiversity conservation and human activities in the central and eastern European countries," Ambio, vol. 36, no. 7, pp. 545-550, 2007.

[7] H. Debela, "Human influence and threat to biodiversity and sustainable living," Ethiopian Journal of Education and Sciences, vol. 3, no. 1, pp. 85-95, 2007.

[8] R. C. Lacy, "Considering threats to the viability of small populations using individual-based models," Ecological Bulletin, vol. 48 , pp. 39-51, 2000.

[9] K. Leus, "Captive breeding and conservation," Zoology in the Middle East, vol. 54, supplement 3, pp. 151-158, 2011.

[10] K. A. Wilson, J. Carwardine, and H. P. Possingham, "Setting conservation priorities," Annals of the New York Academy of Sciences, vol. 1162, pp. 237-264, 2009.

[11] R. Frankham, J. D. Ballou, and D. A. Briscoe, Introduction to Conservation Genetics, Cambridge University Press, Cambridge, UK, 2002.

[12] T. Getachew, "Biodiversity hotspots: pitfalls and prospects," $I B C$ News Letter, vol. 1, pp. 14-16, 2012.

[13] H. Huang, "Plant diversity and conservation in China: planning a strategic bioresource for a sustainable future," Botanical Journal of the Linnean Society, vol. 166, no. 3, pp. 282-300, 2011.

[14] C. Brutting, I. Hensen, and K. Wesche, "Ex situ cultivation affects genetic structure and diversity in arable plants," Plant Biology, vol. 15, pp. 505-513, 2013.

[15] Institute of Biodiversity Conservation, Ethiopia: Second Country Report on the State of PGRFA to FAO, FAO, Rome, Italy, 2007.

[16] E. D. Kjaer, L. Graudal, and I. Nathan, Ex Situ Conservation of Commercial Tropical Trees: Strategies, Options and Constraints, Danida Forest Seed Centre, Humlebaek, Denmark, 2001.

[17] J. Hakansson, Genetic Aspects of Ex Situ Conservation: Introductory Paper, Department of Biology, Linköping University, 2004.

[18] G. M. Reid, T. C. Macbeath, and K. Csatadi, "Global challenges in freshwater-fish conservation related to public aquariums and the aquarium industry," International Zoo Yearbook, vol. 47, pp. 6-45, 2013.

[19] V. A. Melfi, "Ex situ gibbon conservation: status, management and birth sex ratios," International Zoo Yearbook, vol. 46, no. 1, pp. 241-251, 2012.

[20] C. Ratledge, "Towards conceptual framework for wildlife Tourism," Tourism Management, vol. 22, pp. 31-40, 2001. 
[21] J. Balcombe, "Animal pleasure and its moral significance," Applied Animal Behaviour Science, vol. 118, no. 3-4, pp. 208-216, 2009.

[22] S. F. Carrizo, K. G. Smith, and W. R. T. Darwall, "Progress towards a global assessment of the status of freshwater fishes (Pisces) for the IUCN Red List: application to conservation programmes in zoos and aquariums," International Zoo Yearbook, vol. 47, pp. 46-64, 2013.

[23] R. C. Lacy, "Achieving true sustainability of zoo populations," Zoo Biology, vol. 32, pp. 19-26, 2013.

[24] R. L. Eaton, "An overview of zoo goals and exhibition principles," International Journal for the Study of Animal Problems, vol. 2, pp. 295-299, 1981.

[25] E. J. Fernandez, M. A. Tamborski, S. R. Pickens, and W. Timberlake, "Animal-visitor interactions in the modern zoo: conflicts and interventions," Applied Animal Behaviour Science, vol. 120, no. 1-2, pp. 1-8, 2009.

[26] L. A. Dickie, “The sustainable zoo: an introduction," International Zoo Yearbook, vol. 43, no. 1, pp. 1-5, 2009.

[27] A. M. Claxton, "The potential of the human-animal relationship as an environmental enrichment for the welfare of zoo-housed animals," Applied Animal Behaviour Science, vol. 133, no. 1-2, pp. $1-10,2011$.

[28] S. E. Williams and E. A. Hoffman, "Minimizing genetic adaptation in captive breeding programs: a review," Biological Conservation, vol. 142, no. 11, pp. 2388-2400, 2009.

[29] R. J. Whittington and R. Chong, "Global trade in ornamental fish from an Australian perspective: the case for revised import risk analysis and management strategies," Preventive Veterinary Medicine, vol. 81, no. 1-3, pp. 92-116, 2007.

[30] D. Dudgeon, A. H. Arthington, M. O. Gessner et al., "Freshwater biodiversity: importance, threats, status and conservation challenges," Biological Reviews of the Cambridge Philosophical Society, vol. 81, no. 2, pp. 163-182, 2006.

[31] S. Blackmore, M. Gibby, and D. Rae, "Strengthening the scientific contribution of botanic gardens to the second phase of the Global Strategy for Plant Conservation," Botanical Journal of the Linnean Society, vol. 166, no. 3, pp. 267-281, 2011.

[32] A. G. Clarke, "The Frozen Ark Project: the role of zoos and aquariums in preserving the genetic material of threatened animals," International Zoo Yearbook, vol. 43, no. 1, pp. 222-230, 2009.

[33] O. A. Ryder, A. McLaren, S. Brenner, Y.-P. Zhang, and K. Benirschke, "DNA banks for endangered animal species," Science, vol. 288, no. 5464, pp. 275-277, 2000.

[34] C. W. Vertuccj, "Predicting the optimum storage conditions for seeds using thermodynamic principles," Journal of Seed Technology, vol. 17, pp. 41-52, 1993.

[35] R. H. Ellis and E. H. Roberts, "Improved equations for the prediction of seed longevity," Annals of Botany, vol. 45, no. 1, pp. 13-30, 1980.

[36] J. B. Dickie, R. H. Ellis, H. L. Kraak, K. Ryder, and P. B. Tompsett, "Temperature and seed storage longevity," Annals of Botany, vol. 65, no. 2, pp. 197-204, 1990.

[37] M. L. Moir, P. A. Vesk, K. E. C. Brennan et al., "Considering extinction of dependent species during translocation, ex situ conservation, and assisted migration of threatened hosts," Conservation Biology, vol. 26, no. 2, pp. 199-207, 2012.

[38] S. Christie, "Why keep tigers in zoos?" in Tigers of the World: The Science, Politics and Conservation of Panthera Tigris, R. Tilson and P. Nyhus, Eds., pp. 205-214, Elsevier Inc., Amsterdam, The Netherlands, 1998.
[39] U. S. Anderson, A. S. Kelling, R. Pressley-Keough, M. A. Bloomsmith, and T. L. Maple, "Enhancing the zoo visitor's experience by public animal training and oral interpretation at an otter exhibit," Environment and Behavior, vol. 35, no. 6, pp. 826-841, 2003.

[40] H. R. Jensen, A. Dreiseitl, M. Sadiki, and D. J. Schoen, “The Red Queen and the seed bank: pathogen resistance of ex situ and in situ conserved barley," Evolutionary Applications, vol. 5, no. 4, pp. 353-367, 2012.

[41] G. R. Hosey, "How does the zoo environment affect the behaviour of captive primates?" Applied Animal Behaviour Science, vol. 90, no. 2, pp. 107-129, 2005.

[42] K. N. Morgan and C. T. Tromborg, "Sources of stress in captivity," Applied Animal Behaviour Science, vol. 102, no. 3-4, pp. 262-302, 2007.

[43] B. O. Braastad, "Effects of prenatal stress on behaviour of offspring of laboratory and farmed mammals," Applied Animal Behaviour Science, vol. 61, no. 2, pp. 159-180, 1998.

[44] S. M. Wisely, R. M. Santymire, T. M. Livieri et al., "Environment influences morphology and development for in situ and ex situ populations of the black-footed ferret (Mustela nigripes)," Animal Conservation, vol. 8, no. 3, pp. 321-328, 2005.

[45] K. Helenurm and L. S. Parsons, "Genetic variation and the reintroduction of Cordylanthus maritimus ssp. maritimus to Sweetwater Marsh, California," Restoration Ecology, vol. 5, no. 3, pp. 236-244, 1997.

[46] D. Lauterbach, M. Burkart, and B. Gemeinholzer, "Rapid genetic differentiation between ex situ and their in situ source populations: an example of the endangered Silene otites (Caryophyllaceae)," Botanical Journal of the Linnean Society, vol. 168, no. 1, pp. 64-75, 2012.

[47] A. Balmford, G. M. Mace, and N. Leader-Williams, "Designing the ark: setting priorities for captive breeding," Conservation Biology, vol. 10, no. 3, pp. 719-727, 1996.

[48] R. A. Griffiths and L. Pavajeau, "Captive breeding, reintroduction, and the conservation of amphibians," Conservation Biology, vol. 22, no. 4, pp. 852-861, 2008.

[49] R. J. Probert, M. I. Daws, and F. R. Hay, "Ecological correlates of ex situ seed longevity: a comparative study on 195 species," Annals of Botany, vol. 104, no. 1, pp. 57-69, 2009.

[50] L. M. Clayton, E. J. Milner-Gulland, D. W. Sinaga, and A. H. Mustari, "Effects of a proposed ex situ conservation program on in situ conservation of the babirusa, an endangered suid," Conservation Biology, vol. 14, no. 2, pp. 382-385, 2000.

[51] W. G. Conway, "Buying time for wild animals with zoos," Zoo Biology, vol. 30, no. 1, pp. 1-8, 2011.

[52] N. C. Ellstrand and D. R. Elam, "Population genetic conseqences of small population size: implications for plant conservation," Annual Review of Ecology and Systematics, vol. 24, pp. 217-242, 1993.

[53] A. A. Cunningham, "Disease risks of wildlife translocations," Conservation Biology, vol. 10, no. 2, pp. 349-353, 1996.

[54] R. P. Reading, T. W. Clark, and B. Griffith, "The influence of valuational and organizational considerations on the success of rare species translocations," Biological Conservation, vol. 79, no. 2-3, pp. 217-225, 1997.

[55] L. I. Wright, T. Tregenza, and D. J. Hosken, "Inbreeding, inbreeding depression and extinction," Conservation Genetics, vol. 9, no. 4, pp. 833-843, 2008.

[56] B. Miller, K. Ralls, R. P. Reading, J. M. Scott, and J. Estes, "Biological and technical considerations of carnivore translocation: a review," Animal Conservation, vol. 2, no. 1, pp. 59-68, 1999. 
[57] L. Laikre, L. C. Larsson, A. Palmé, J. Charlier, M. Josefsson, and N. Ryman, "Potentials for monitoring gene level biodiversity: using Sweden as an example," Biodiversity and Conservation, vol. 17, no. 4, pp. 893-910, 2008.

[58] N. I. Vavilov, "The origin, variation, immunity and breeding of cultivated plants," Chronica Botanica, vol. 13, pp. 1-366, 1951.

[59] S. Demissew, "How has government policy post-global strategy for plant conservation impacted on science? The Ethiopian perspective," Botanical Journal of the Linnean Society, vol. 166, no. 3, pp. 310-325, 2011.

[60] B. Girma, T. Pearce, and D. Abebe, "Biological diversity and current ex situ conservation practices in Ethiopia," in Seed Conservation Turning Science into Practice, R. D. Smith, J. B. Dickie, S. H. Linington, H. W. Pritchard, and R. J. Probert, Eds., pp. 849-856, Kew Publishing, Kew, UK, 2003. 

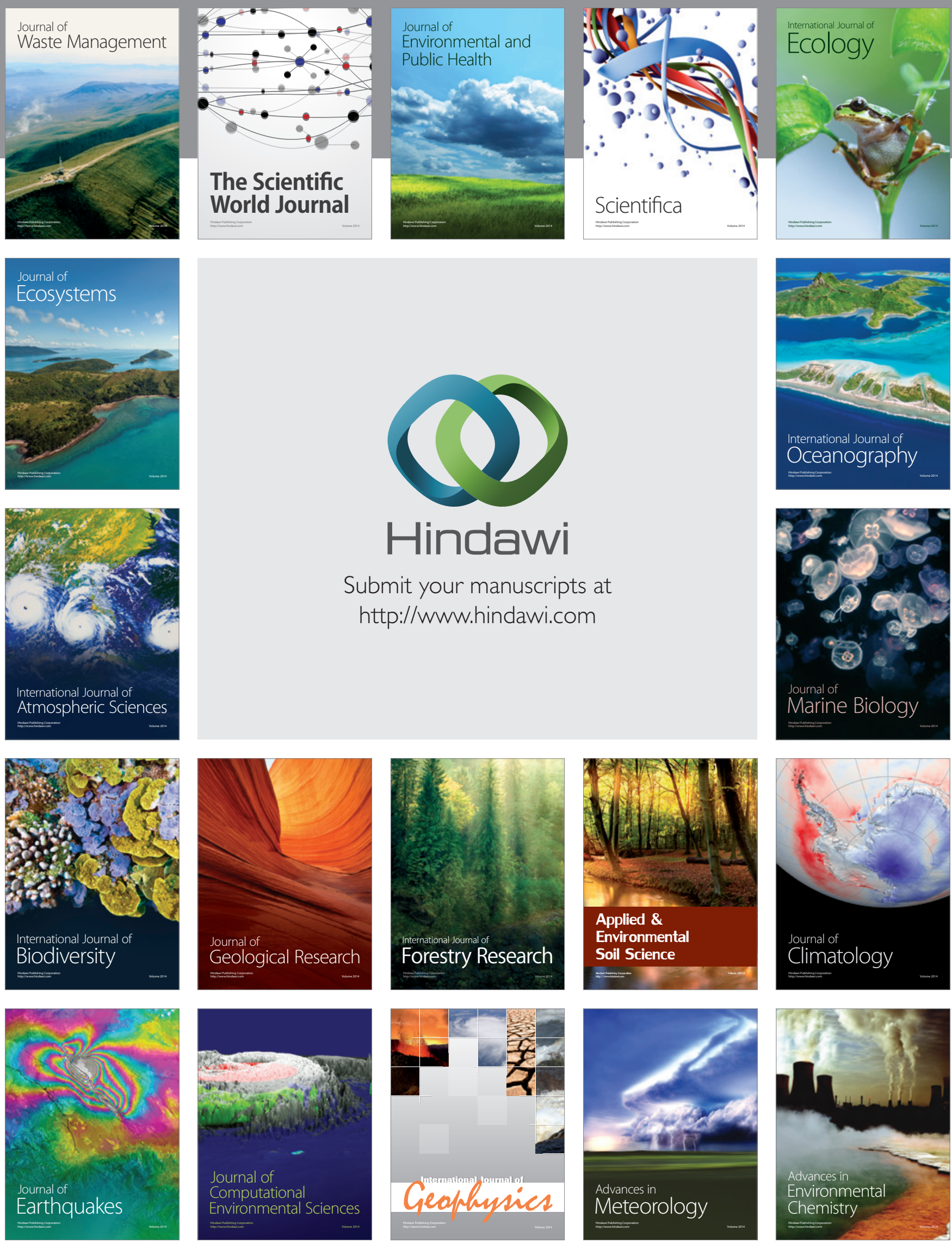